\title{
Progressive spinocerebellar degeneration "plus" associated with Langerhans cell histiocytosis: a new paraneoplastic syndrome?
}

\author{
H Goldberg-Stern, R Weitz, R Zaizov, M Gornish, N Gadoth
}

\begin{abstract}
Langerhans cell histiocytosis (LCH), formerly known as histiocytosis-X, manifests by granulomatous lesions consisting of mixed histiocytic and eosinophilic cells. The hallmark of LCH invasion into the CNS is diabetes insipidus, reflecting local infiltration of Langerhans cells into the posterior pituitary or hypothalumus.

In five patients who had early onset LCH with no evidence of direct invasion into the CNS, slowly progressive spinocerebellar degeneration accompanied in some by pseudobulbar palsy and intellectual decline was seen. Neurological impairment started $2 \cdot 5$ to seven years after the detection of LCH. No correlation was found between the clinical syndrome and location of LCH or its mode of treatment.

An extensive search for metabolic, toxic, neoplastic, and hereditary aetiologies for progressive cerebellar degeneration was negative. It seems that the clinical entity described here may be considered a new paraneoplastic syndrome related to LCH. It may be induced by the eosinophil derived neurotoxin, which was shown to cause damage to Purkinje cells and pyramidal neurons.
\end{abstract}

$(F$ Neurol Neurosurg Psychiatry 1995;58:180-183)

The Felsenstein

Research Center,

Beilinson Medical

Center, Petah Tiqva,

and Sackler Faculty of

Medicine, Tel Aviv

University, Tel Aviv,

Israel

Department of

Neurology

H Goldberg-Stern

$N$ Gadoth

Department of

Pediatric Neurology

R Weitz

Department of

Pediatric Hematology

- Oncolocy

R Zaizov

Department of

Radiology

M Gornish

Correspondence to:

Dr Goldberg-Stern,

Department of Neurology,
Beilinson Medical Center,

Beilinson Medical Center,
Petah Tiqva, 49100, Israel.

Received 2 February 1994

and in revised form

17 June 1994.

Accepted 10 August 1994 enabling the study of long term sequelae of LCH.

Ranson $e t a l^{5}$ reported that about half of his patients with generalised $\mathrm{LCH}$ had "neuropsychiatric disability", and the Southwest Oncology Group reported on 17 out of 56 long term survivors who had a variety of neurological disabilities including cerebellar ataxia in two of them; details of neurological state or neuroimaging studies were not noted. ${ }^{6}$

The present report describes five patients who had extraneural LCH, in whom progressive spinocerebellar syndrome appeared several years after the initial diagnosis.

In all cases the family history was negative and the initial neurological examination, CSF content, and brain imaging at the time of LCH detection were normal. Diabetes insipidus was looked for but never found, neither initially nor during the long term follow up. A meticulous search for known causes of progressive spinocerebellar impairment of young onset was negative in all cases.

\section{Case reports}

PATIENT NO 1

In a previously healthy child, $\mathrm{LCH}$, in the form of eosinophilic granuloma of the left mastoid, was excised at the age of 18 months. There were no symptoms or signs of invasion of the CNS. After operation he was irradiated locally and subsequently developed postradiation necrosis of the left side of his face and sternocleidomastoid muscle resulting in fixed left torticollis and left nerve deafness. His condition remained stable until the age of 4 years, when gradual gait instability appeared. Subsequently, progressive dysarthria developed. Severe motor dysfunction confined him to a wheelchair at the age of 30 years. Recurrent grand mal seizures occurred at the age of 37 years and have been successfully controlled with phenytoin. At the last clinic visit after 36 years of continuous follow up, the cardinal neurological abnormalities included emotional lability with uncontrolled crying, severe dysarthria, gaze directed horizontal nystagmus, abnormal ocular smooth pursuit, slow saccades, generalised hypotonia, symmetric hyperreflexia, mild ankle clonus, bilateral extensor plantar response, severe disequilibrium and limb ataxia, and prominent dysmetria.

PATIENT NO 2

A girl was healthy until 3 months of age when 
Patient No 3, a 27 year old man. (A) T1 weighted (TR/TE 440/27) sagittal; and (B) coronal (TR/TE 350/12) $0.5 T M R$ images. Note pronounced atrophy of vermis, cerebellar hemispheres, and pons with mildly prominent cerebral sulci for age.
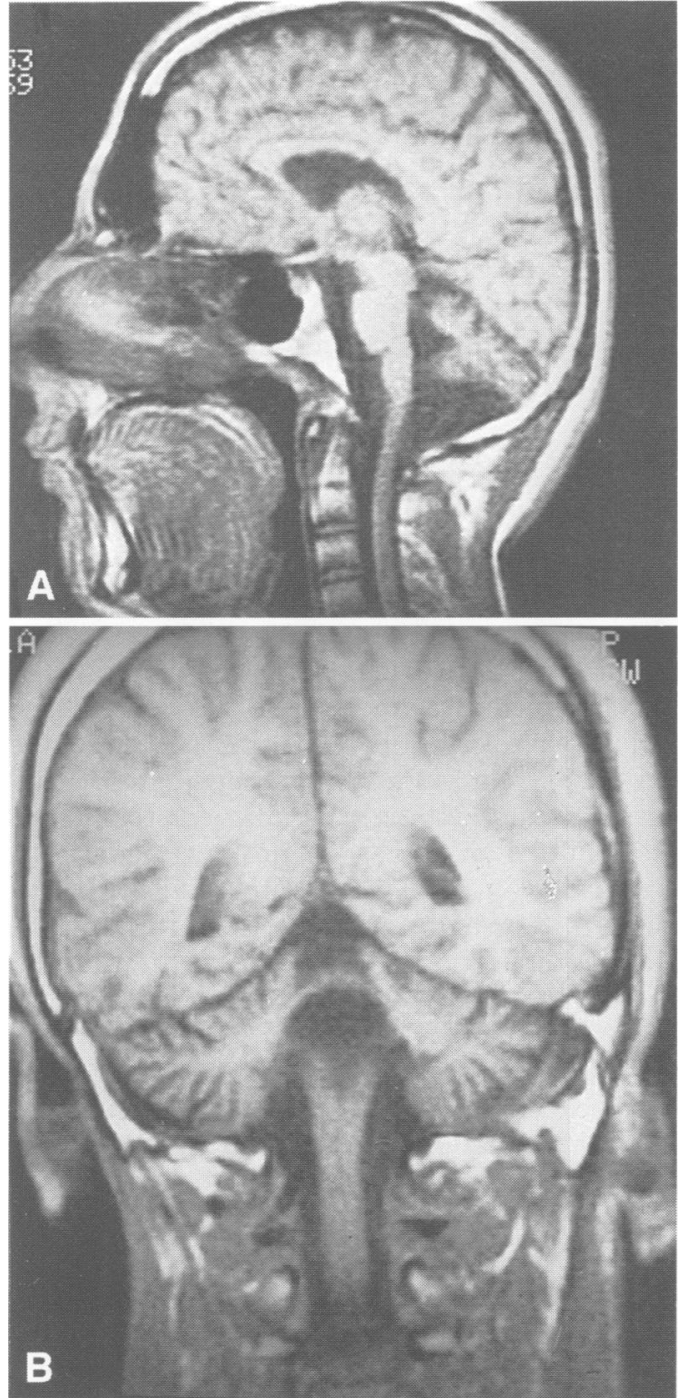

erythematous seborrheic skin rash and purulent otitis were noted. An osteolytic lesion of the left mastoid was seen on skull radiographs. Skin biopsy disclosed typical LCH. The neurodevelopmental state, routine laboratory tests, spinal fluid, skeletal radiological survey, and cerebral CT were normal. The family history was negative. She was treated with vinblastine sulphate, cyclosphosphamide, and prednisone divided into 17 single doses during the first year of life. At the age of 3 years and 10 months she started dragging her right leg. A year later she was seen for frequent falls. During the subsequent months, mental deterioration, severe progressive ataxia, limb dysmetria, muscle hypotonia, brisk deep tendon reflexes, and bilateral extensor plantar response were noted.

\section{PATIENT NO 3}

A boy was healthy until 2 years of age when a painful swelling was noted below his right auricle. Skull radiographs disclosed a round osteolytic lesion of the right mastoid, which was excised and found to be LCH, eosinophilic granuloma type. He received a total dose of 750 rads to the affected area and was well until the age of 4 years and 8 months when unsteadiness and a wide based gait were noted. Six months later, pronounced ataxia and gaze directed horizontal nystagmus were found. Progressive intellectual deterioration, confirmed by appropriate psychometric tests, resulted in his transfer to a special education institution. His latest neurological evaluation was performed at the age of 27. At that time an examination of eye movement showed abnormal pursuit with sluggish saccades, inability to maintain lateral gaze, rebound nystagmus, and lack of optokinetic nystagmus.

Brisk deep tendon reflexes with muscle hypotonia in the upper limbs and severe spastic weakness with hyperreflexia in the lower limbs, bilateral ankle clonus, and extensor plantar responses were also present; severe ataxia, dysmetria, cognitive deterioration, and frequent outbursts of uncontrolled laughter were also noted.

PATIENT NO 4

A right handed man had a normal neonatal and early childhood history. A routine examination before army enlistment showed an osteolytic lesion in the right 9 th rib. This was excised and proved to be $\mathrm{LCH}$, eosinophilic granuloma type. Afterwards he completed an uneventful army service. At the age of 21 he noticed gradual onset of disequilibrium with intentional tremor. Neurological examination showed a nasal voice, dysarthria, muscle hypotonia, brisk deep tendon reflexes, bilateral extensor plantar response, and bilateral ankle clonus. The finger to nose, heel-kneeshin, and Romberg tests were greatly impaired. His condition continued to deteriorate very slowly and at the present time he can walk only with canes.

PATIENT NO 5

A 19 year old woman was healthy until the age of 2 years when she had a mild head trauma and was found to have a soft swelling at the right side of her scalp. Skull radiographs and a radiological skeletal survey disclosed multiple lytic bone lesions (biparietal, right proximal femur, and right iliac bone). The diagnosis of $\mathrm{LCH}$, eosinophilic granuloma type was confirmed histologically. No treatment was offered, and she led a normal life until the age of 9 when progressive ataxia with frequent falls was first noted. During the subsequent years mental deterioration, severe disequilibrium and limb ataxia, dysarthria, abnormally brisk deep tendon reflexes, ankle clonus, and bilateral extensor plantar response were noted. During the 10 years of follow up, slow deterioration with no evidence of relapse of disease was documented.

ANCILLARY TESTS

In all five cases routine laboratory tests, including a screen for metabolic errors of childhood, heavy metal storage, CSF composition, EEG, nerve conduction studies, and EMG were normal. In all cases brain CT disclosed mild to moderate cerebellar and pontine atrophy, symmetric dilatation of the ventricular system, and mild cerebral cortical atrophy. Similar findings were obtained in 
patients $1-4$ by MRI. Neither masses, nor hyperintense signals on T2 weighted images were detected. No gadolinium enhanced images were obtained. During the long follow up, additional CT and MRI were almost identical to the initial studies in case 1 . In patients $2-4$, slow progression of imaging abnormalities was evident. The most striking changes were seen in patient No 2 . Initial studies were almost normal, but the typical radiological picture evolved during the next five to six years.

The serum samples and CSF of patients Nos 1, 3, and 4 did not contain antibodies to Purkinje cells.

\section{Discussion}

In 1985 we first reported four cases with late neurological deterioration associated with LCH with no evidence of disease invasion into the nervous system. ${ }^{7}$ In the present report we have completed a follow up period ranging from 10 to 36 years and have added an additional patient.

Of the five patients described, four had the localised form of $\mathrm{LCH}$, eosinophilic granuloma type and one had the diffuse type with mastoid lesions and skin involvement. The diagnosis in each case was confirmed histologically. The bony lesions were excised in four patients (with addition of local irradiation in two). Patient No 2, with the generalised form of the disease, was the only one who received chemotherapy. All patients developed signs of progressive spinocerebellar impairment 2.5 to seven years after the initial diagnosis.

Neurological findings consisted of severe cerebellar ataxia, brisk deep tendon reflexes, and bilateral extensor plantar responses. In three patients intellectual deterioration and in two pseudobulbar signs subsequently appeared (table). The neuroradiological findings in all cases were similar and showed cerebellar and pontine atrophy with no signs of demyelination on MRI and no evidence of disease invasion.

An extensive search for hereditary, metabolic, neoplastic, immunological, and toxic aetiologies was negative. No correlation was found between the clinical syndrome and the location of the lesion or its mode of treatment. The normal CSF protein, metabolic screen,
EMG, and nerve conduction studies together with the negative family history helped in excluding the hereditary progressive cerebellar atrophies of young age.

Diabetes insipidus and other endocrine abnormalities resulting from hypothalamic or pituitary invasion of tumour cells are the most common neurological manifestations of $\mathrm{LCH} .{ }^{48}$ Among the extradiencephalic sites of this disease, the cerebellum seems to be the most vulnerable. ${ }^{4}$ Recently, a diffuse infiltration of the CNS by Langerhans cells was reported. ${ }^{9}$

Grois et al summarised 72 cases with LCH and CNS complications reported since $1924 .{ }^{10}$ In $72 \%$ those symptoms started a few years after the onset of LCH. The most frequent presentation was spinocerebellar impairment, as in our cases. In all patients there was evidence of invasion of the CNS manifested by diabetes insipidus or intraparencyhmatous infiltration into the cerebrum, cerebellum, etc, detected by neuroimaging or necropsy. ${ }^{11-14}$

Our cases are unique in that they lacked evidence of cranial or brain parenchymatous spread at the time of initial diagnosis or during the long term follow up. Rosenfeld et al described the neuroimaging features of eight patients with $\mathrm{LCH}$ who had neurological manifestations. Their case No 4 showed clinical and radiological signs of progressive cerebellar degeneration without evidence of invasion of the CNS. ${ }^{15}$ We believe that this case resembles our patients. Kepes ${ }^{4}$ stated that a possible mechanism for neurological dysfunction without direct spread of Histiocytosis- $X$ into the CNS may be secondary demyelination. The absence of hyperintense signals on the T2 weighted MRI in our patients, however, excludes this assumption. As patients with skull lesions have occasionally received radiotherapy, the possibility that cerebellar degeneration is a delayed effect of radiation was considered..$^{10}$ The presence of clinical and radiological cerebellar degeneration in cases that were never irradiated exclude this possibility.

Considering that progressive spinocerebellar dysfunction in our patients could not be attributed to currently known aetiologies and that it is not caused by tumour invasion, the possibility that a remote effect of $\mathrm{LCH}$ caused

\section{Clinical manifestations of patients}

\begin{tabular}{|c|c|c|c|c|c|c|c|}
\hline $\begin{array}{l}\text { Patient } \\
\text { No }\end{array}$ & Sex & $\begin{array}{l}\text { Age at } \\
\text { LCH } \\
\text { diagnosis } \\
(y)\end{array}$ & $\begin{array}{l}\text { Location of } \\
\text { granulomas }\end{array}$ & Treatment & $\begin{array}{l}\text { Age at onset of } \\
\text { neurological } \\
\text { impairment } \\
\text { (y) }\end{array}$ & $\begin{array}{l}\text { Duration of } \\
\text { neurological } \\
\text { disease }\end{array}$ & $\begin{array}{l}\text { Neurological } \\
\text { signs }\end{array}$ \\
\hline 1 & $M$ & $18 / 12$ & Left mastoid & $\begin{array}{l}\text { Excision and local } \\
\text { irradiation }\end{array}$ & 4 & 36 & $\begin{array}{l}\text { SCD } \\
\text { Seizures } \\
\text { PBP }\end{array}$ \\
\hline 2 & $\mathrm{~F}$ & $3 / 12$ & Skin, left mastoid & Chemotherapy & $310 / 12$ & 10 & $\begin{array}{l}\text { SCD } \\
\text { MD }\end{array}$ \\
\hline 3 & $\mathbf{M}$ & 2 & Right mastoid & $\begin{array}{l}\text { Excision and local } \\
\text { irradiation }\end{array}$ & $48 / 12$ & 22 & $\begin{array}{l}\text { SCD } \\
\text { MD } \\
\text { PBP }\end{array}$ \\
\hline 4 & $M$ & 18 & Right 9th rib & Excision & 21 & 20 & $\begin{array}{l}\text { SCD } \\
\text { PBP }\end{array}$ \\
\hline 5 & $\mathbf{F}$ & 2 & $\begin{array}{l}\text { Biparietal } \\
\text { Right proximal femur } \\
\text { Right iliac bone }\end{array}$ & $\begin{array}{l}\text { Excision of } \\
\text { skull lesion }\end{array}$ & 9 & 10 & $\begin{array}{l}\text { SCD } \\
\text { MD }\end{array}$ \\
\hline
\end{tabular}

SCD = Spinocerebellar degeneration; $\mathrm{MD}=$ mental deterioration; $\mathrm{PBP}=$ pseudobulbar palsy 
the late neurological impairment should be entertained.

The lesions of LCH consist of mixed histiocytic and eosinophilic infiltrates with varying multinucleated giant cells. It has been suggested that LCH may represent an uncontrolled immunological reaction to an unknown antigen. ${ }^{16}$ In 1932, Gordon reported that injecting rabbits intracerebrally with lymph node suspension obtained from patients with Hodgkin's disease caused ataxia and muscle paralysis after two to 20 days. The histopathological findings consisted mainly of damage to Purkinje cells, with a lesser hippocampal and pyramidal neuronal involvement. ${ }^{17}$

Further information on the potential tissue damaging effects of eosinophils has emerged from precise delineation of the unique intracytoplasmic content of the eosinophilic granules.

It was shown that intracerebral injection of eosinophil derived neurotoxin, a glycosylated protein with ribonuclease like activity can cause ataxia and limb paralysis in experimental animals probably by inactivation of protein synthesis. ${ }^{18}$ Necropsy studies show that the neurotoxin damages mainly Purkinje cells, pyramidal neurons, and myelin.

The fact that the median time of onset of neurological findings after the detection of $\mathrm{LCH}$ in our patients was 3.5 (range $2 \cdot 5-7$ ) years is compatible with the concept of paraneoplastic syndromes according to Posner, ${ }^{19}$ who stated that a remote effect of cancer implies any nervous system dysfunction that is not caused by direct invasion or metastases. There is no limitation of time between the appearance of the neurological deficit and the neoplastic process or vice versa. Although no antibodies against Purkinje cells or other neuronal elements were found in our cases and others $^{10}$ the possibility that the damage is mediated by an autoimmune mechanism was not excluded.

We believe that in patients with cured extraneural $\mathrm{LCH}$, progressive neurological impairment manifested mainly by spinocere- bellar degeneration may be considered a remote effect on the nervous system, by a mechanism as yet unknown.

1 Lichtenstein L. Histiocytosis X. Integration of eosinophilic granuloma of bone, "Letterer-Siwe disease" and "Schuller-Christian syndrome" as related manifestations of a single nosologic entity. Arch Pathol 1953;56:84-102. 2 Broadbent V, Gadner H, Komp DM, Ladisch S. Histiocytosis syndromes in children. II: Approach to the clinical and laboratory evaluation of children with Langerhans cell histiocytosis. Med Pediatr Oncol 1989; 17:492-5.

3 Yarbro JW. The histiocytic syndromes. Semin Oncol 1991; 18:1.

4 Kepes JJ. Histiocytosis-X. In: Vinken JH, Bruyn GW, eds. Handbook of clinical neurology. Vol 38, Part 1, Amsterdam: Elsevier, 1979:93-117.

5 Ranson LJ, Powazek M, Goff JR, et al. Neuropsychological late sequelae of histiocytosis-X [abstract]. Pediatr Res late sequelae

6 Komp DM, El Mahdi A, Starling KA, et al. Quality of survival in histiocytosis-X: a Southwest Oncology Group study. Med Pediatr Oncol 1980;8:35-40.

7 Gadoth N, Weitz R, Zaizov R, Vogel R, Bechar M. Long term neurological sequelae of localized eosinophilic granuloma [abstract]. $\mathcal{f}$ Neurol 1985;232(suppl 1):21.

8 Beard W, Foster DB, Kepes J, Guillan RA. Xanthomatosis of the central nervous system. Clinical and pathological observations of a case with a posterior fossa syndrome. Neurology 1970;20:305-14.

9 Hasegawa K, Mitomi T, Kowa TP, Mootoori T, Yagisita S. A clinico-pathological study of adult histiocytosis-x involving the brain. $f$ Neurol Neurosurg Psychiatry

10 Grois N, Barkovich J, Rosenau W, Ablin AR. Central nervous system disease associated with Langerhans' cell histiocytosis. Am F Pediatr Hematol Oncol 1993;15:245-54.

11 Braunstein GD, Whitaker JN, Kohler PO. Cerebellar dysfunction in Hand-Schuller-Christian disease. Arch Intern Med 1973;132:387-90.

12 Adornato BT, Eil C, Head GL, Loridux LD. Cerebellar involvement in multifocal eosinophilic granuloma: demonstration by computerized tomography scanning. Ann Neurol 1980;7:125-9.

13 Amirdjazil Z, Serban-Aurel E, Konard K. Histiocytosis-X in an adult with skin and uncommon central nervous system involvement. Dermatologica 1977;155:283-91.

14 Burn DJ, Waston JDG, Roddie M, Chu AC, Legg NJ, Frackowiak RSJ. Langerhan's cell histiocytosis and the nervous system. F Neurol 1992;239:345-50.

15 Rosenfield J, Komp AJ. Brain MRI in patients with Langerhans cell histiocytosis: findings and enhancement Langerhans cell histiocytosis: findings and enhanc

16 Ladisch S, Jaffe ES. The histiocytoses. In: Pizzo PA, Poplack DG, eds. Principles and practice of pediatric Oncology, 2nd ed. Philadelphia: Lippincot, 1993: 491-505.

17 Fredens K, Dahl R, Venge P. The Gordon phenomenon induced by the eosinophil cationic protein and eosinophil protein X. F Allergy Clin Immunol 1982;70: $361-6$.

18 Durack DT, Sumi SM, Klebanoff JS. Neurotoxicity of human eosinophils. Proc Natl Acad Sci USA 1979;76: 1443-7.

19 Posner JB. Paraneoplastic syndromes. Neurologic complications of systemic cancer. Neurologic Clinics of North America 1991;9:919-36. 